\title{
AS DINÂMICAS DE RECIPROCIDADE DOS SERES HUMANOS E NÃO-HUMANOS NOS MORROS VIVOS DE PIXAIM
}

\author{
WALDSON DE SOUZA COSTA ${ }^{1}$
}

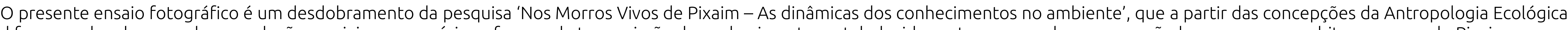

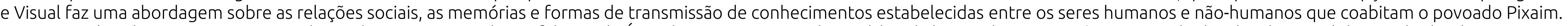

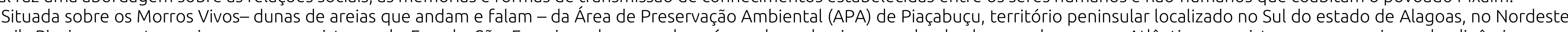

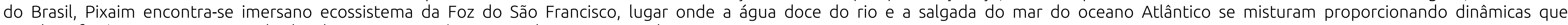
envolvemfenômenos que são resultados da interação simétrica entre humanos e não-humanos.

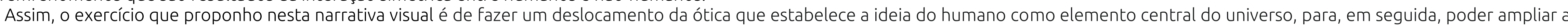

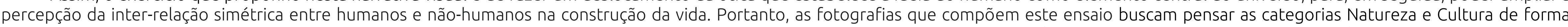

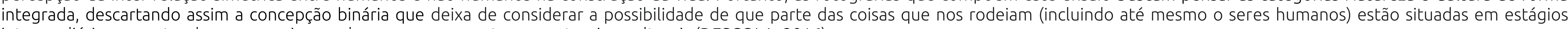
intermediários, ao entender que as coisas podem ser ao mesmo tempo naturais e culturais (DESCOLA, 2016).

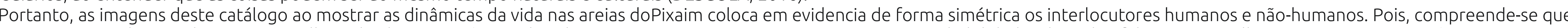

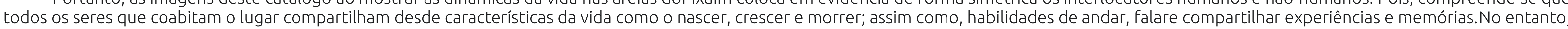

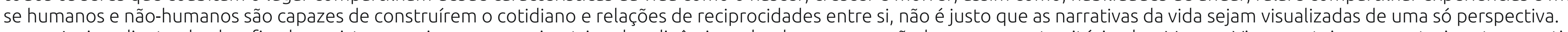

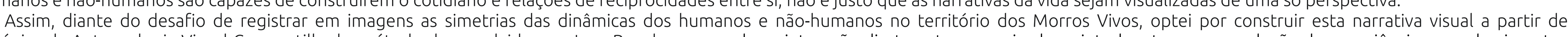

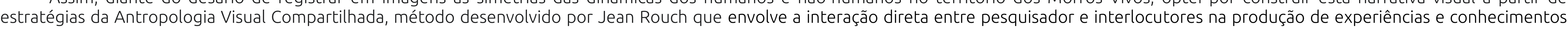
estruturados.

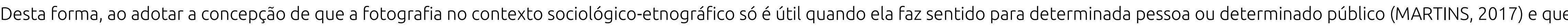

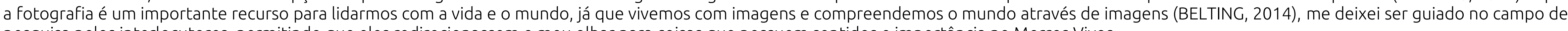
pesquisa pelos interlocutores, permitindo que eles redirecionassem o meu olhar para coisas que possuem sentidos e importância no Morros Vivos.

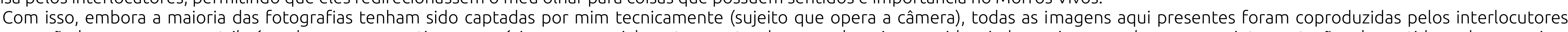

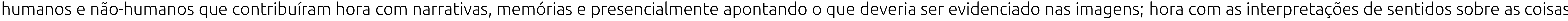
que haviam sido captadas pela câmera e transformada em fotografia no papel. 


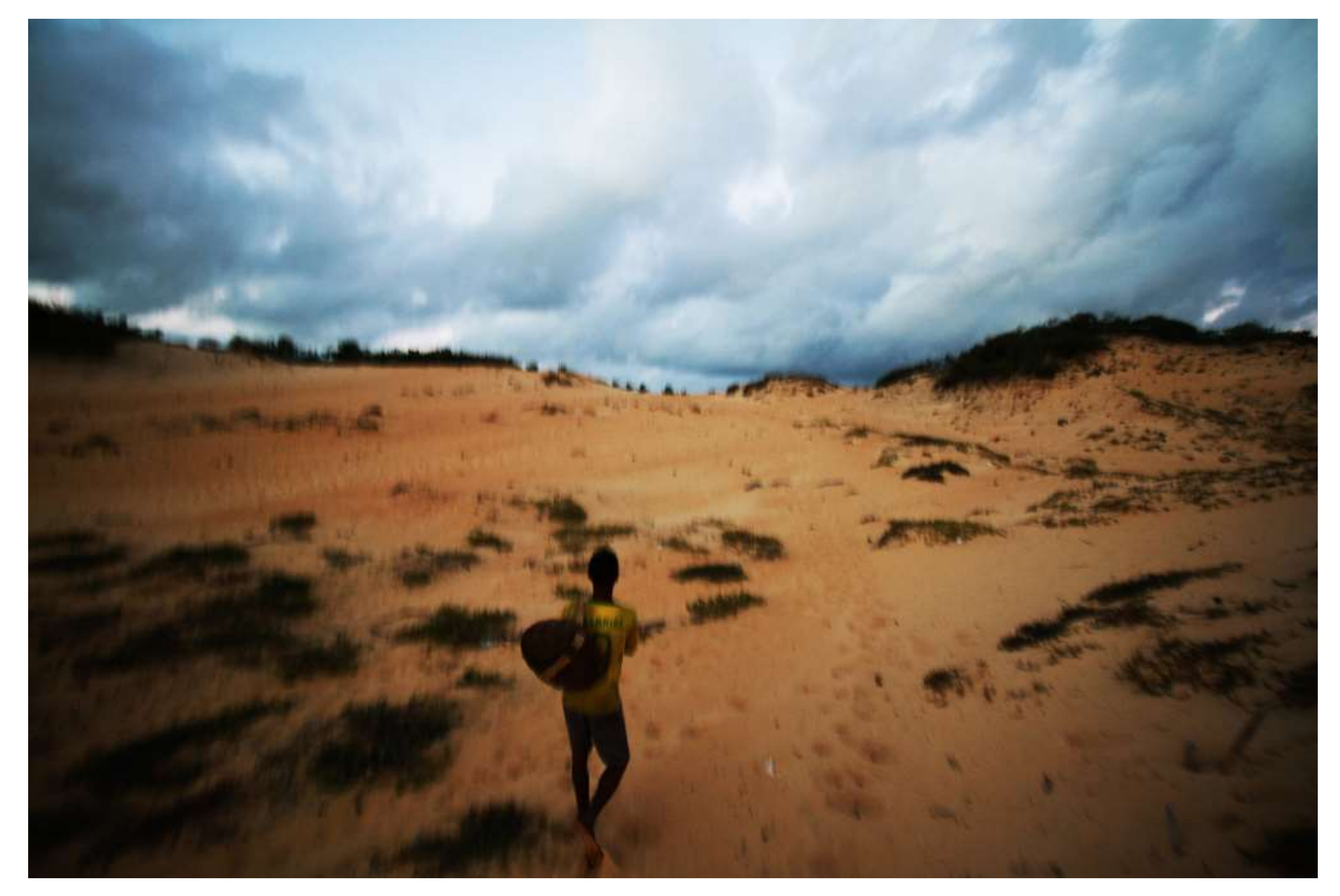




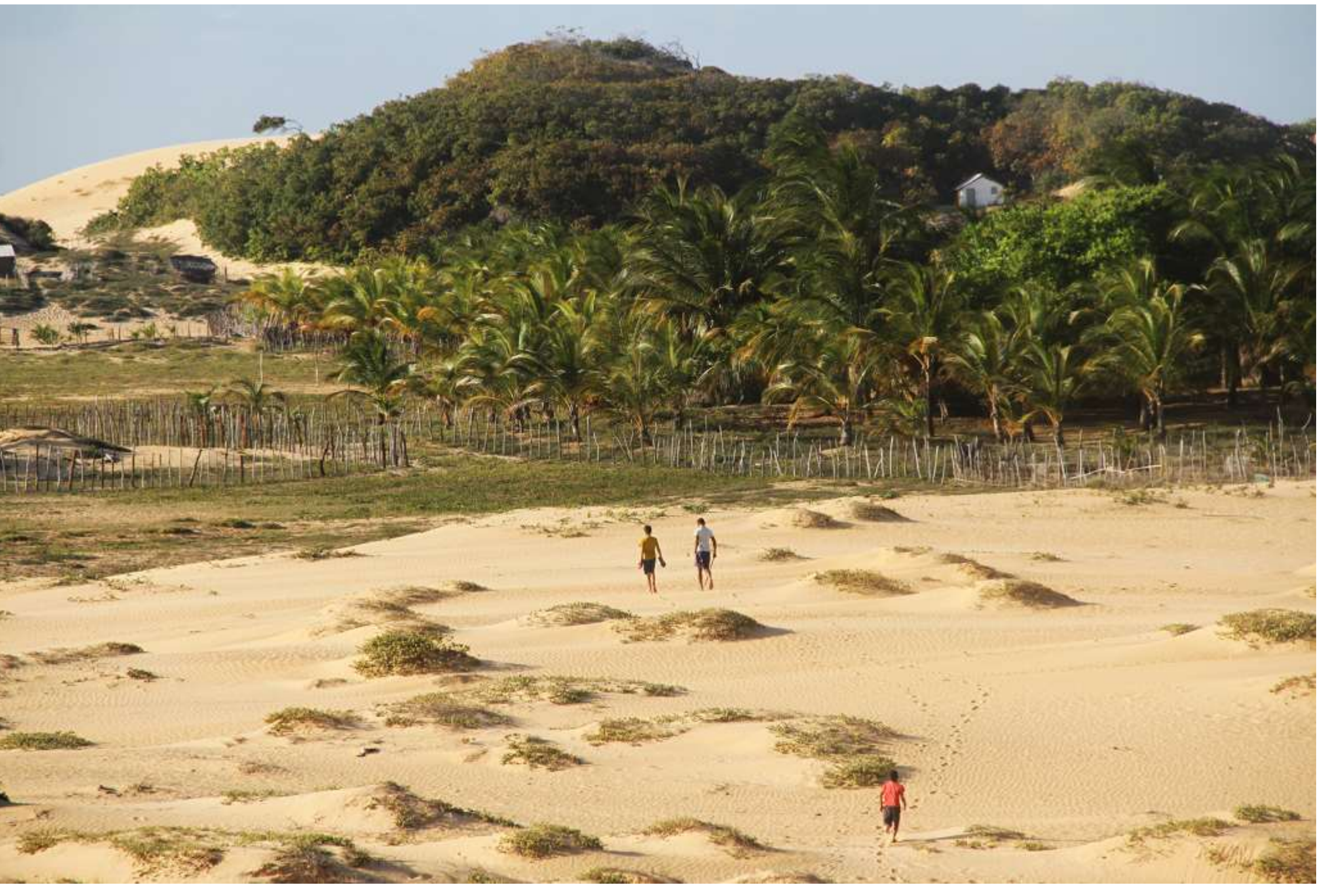




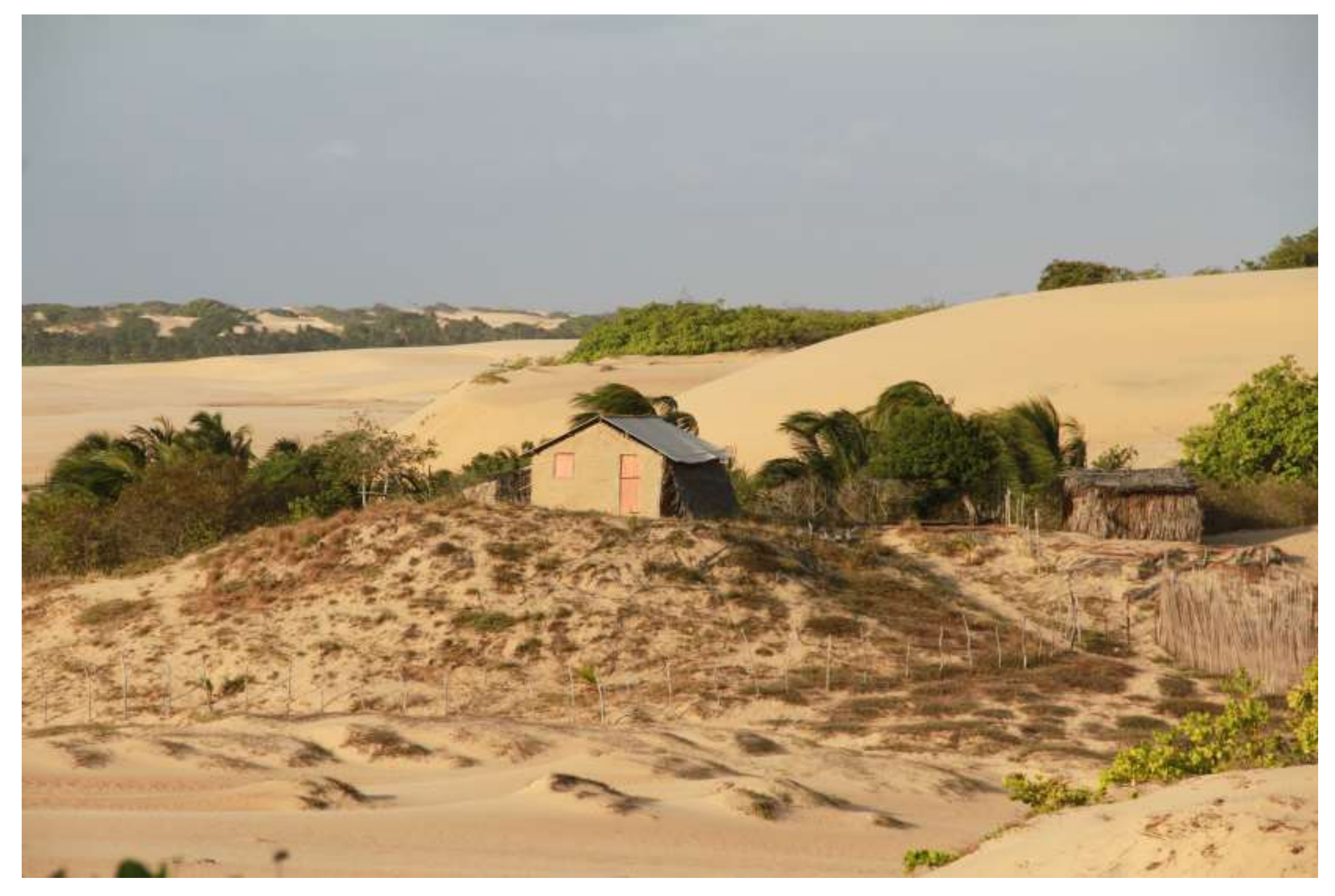

ก

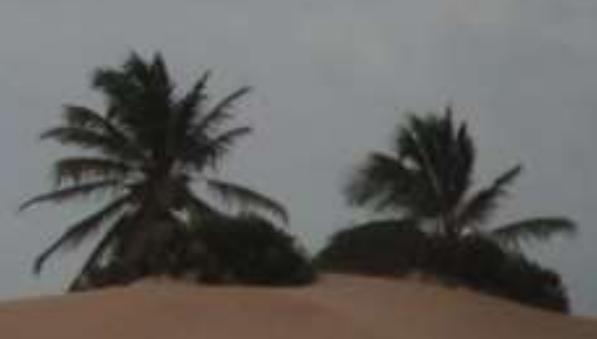




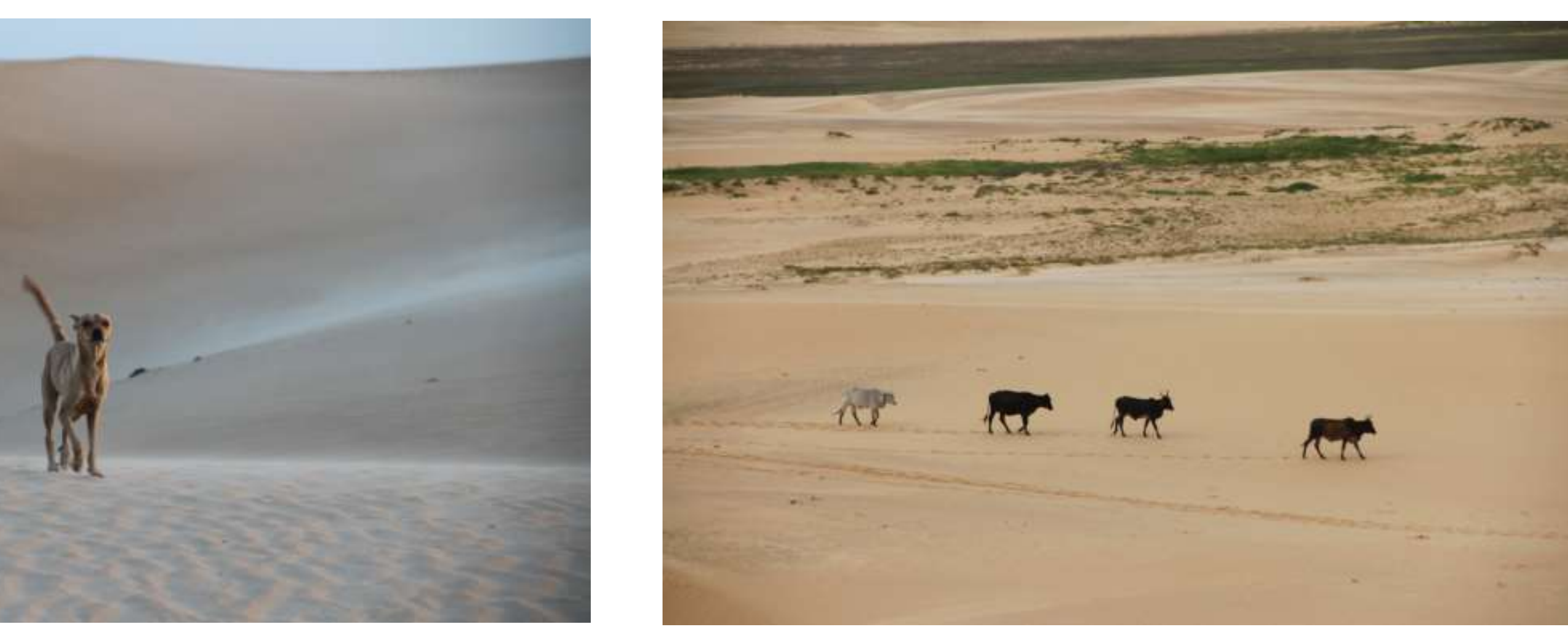

"th

Aㅎ 


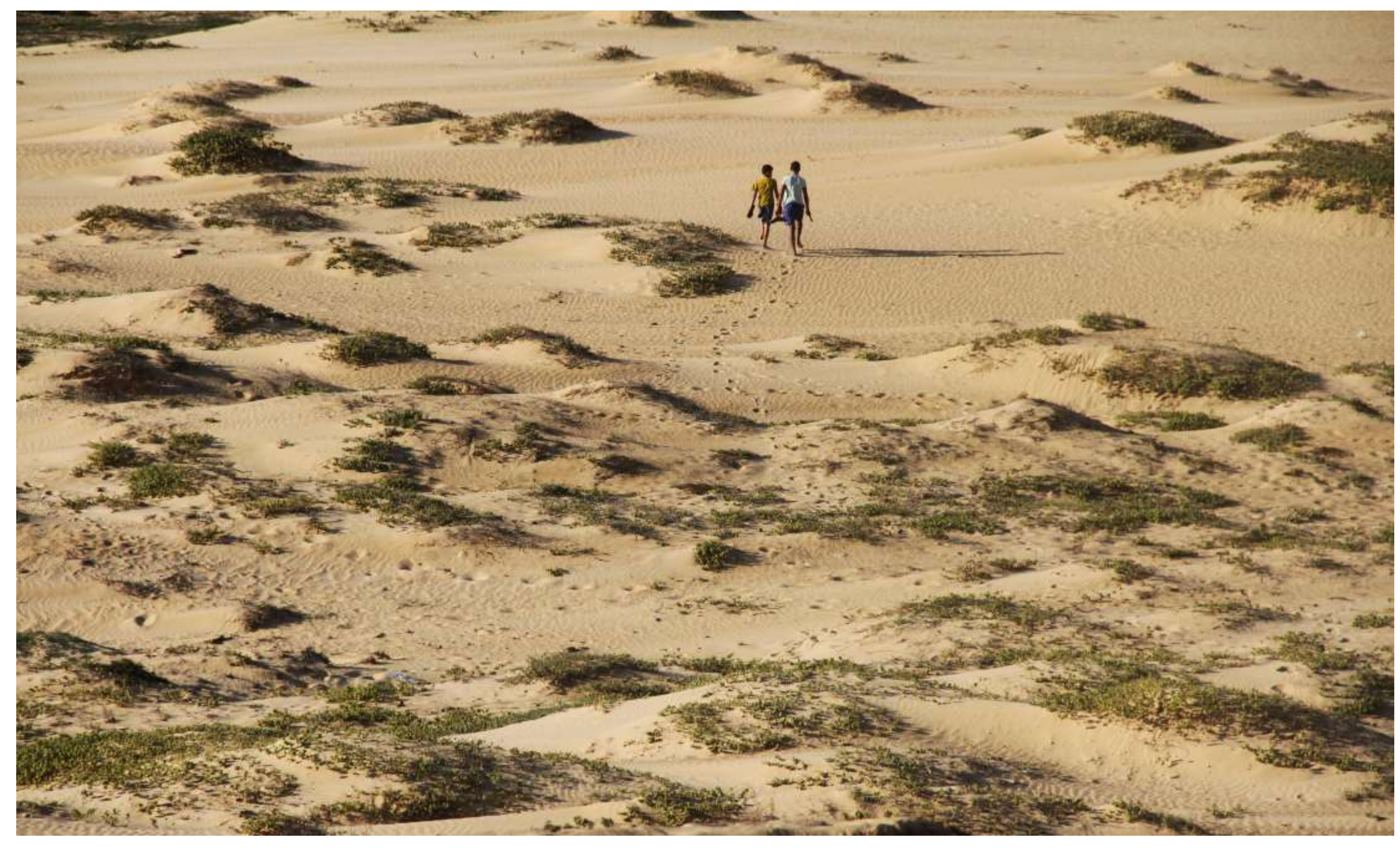



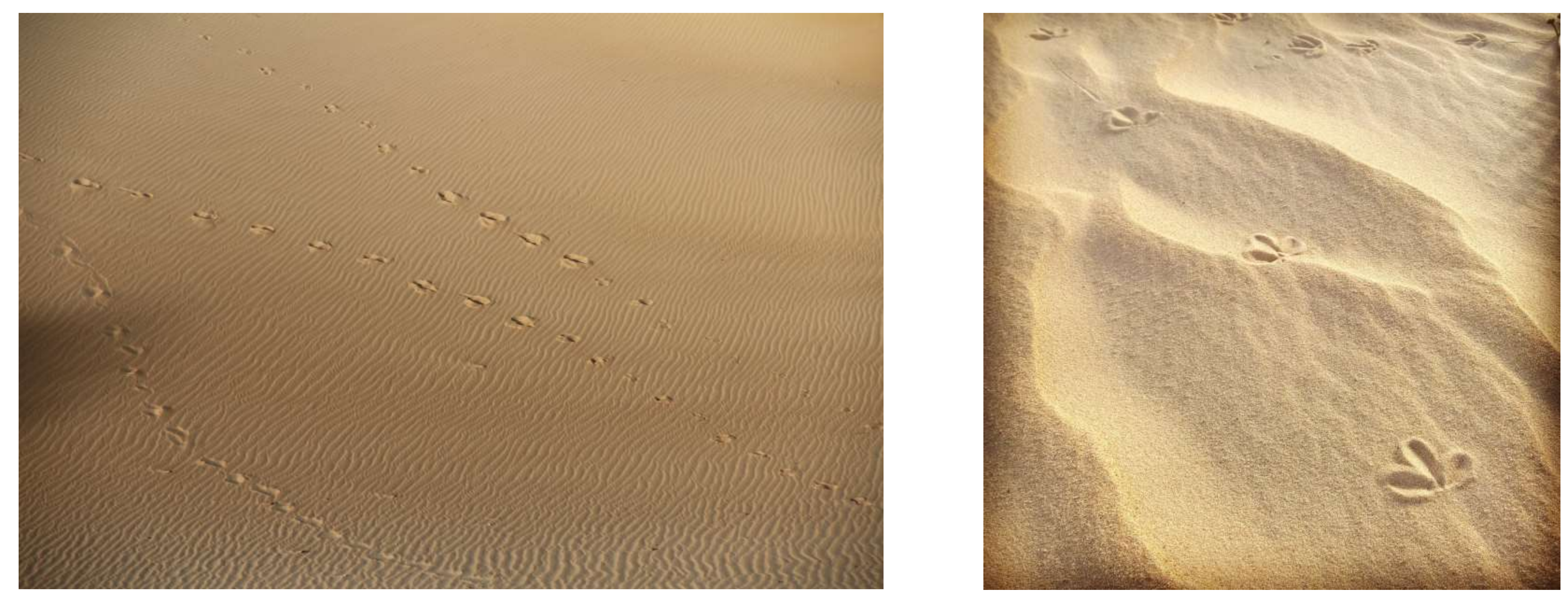


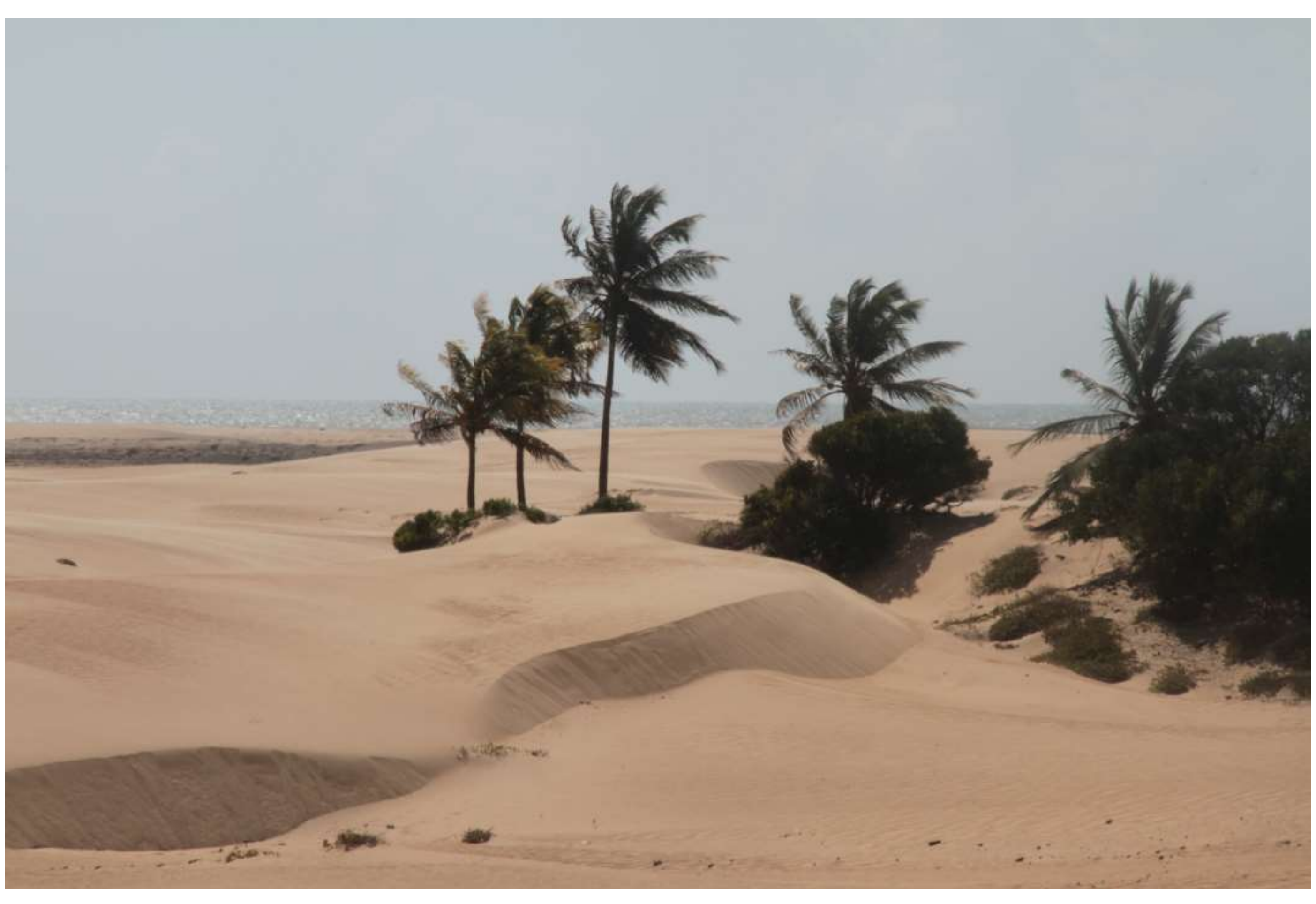



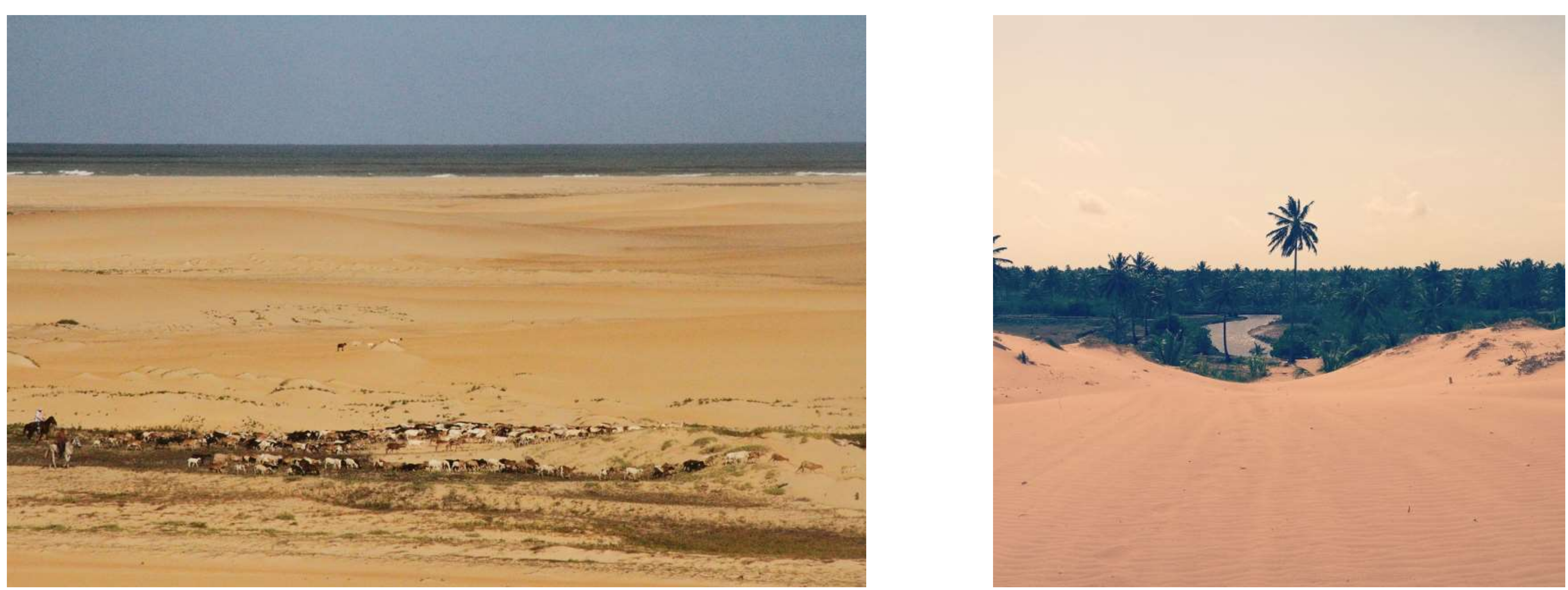


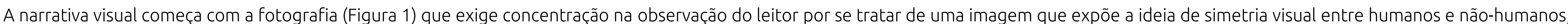

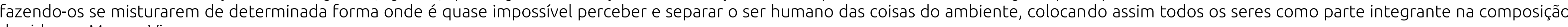
da vida nos Morros Vivos.

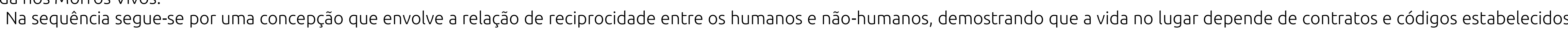

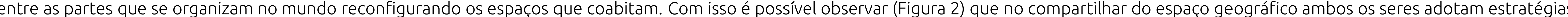

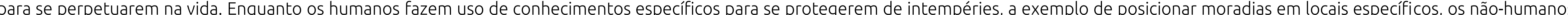

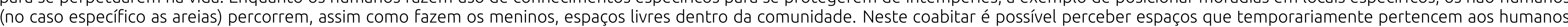

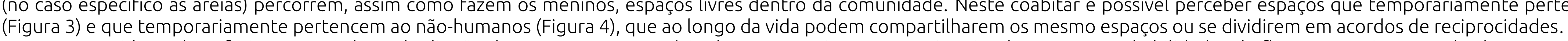

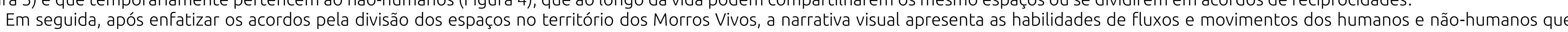

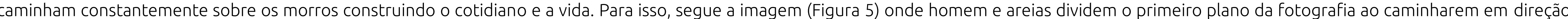
oposta. Há neste processo também a presença do fluxo de animais (Figuras 6 e 7), que também compartilham o caminhar sobre as areias assim como fazem os humanos (Figura 8 ).

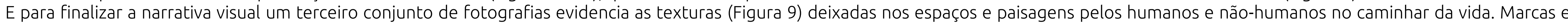

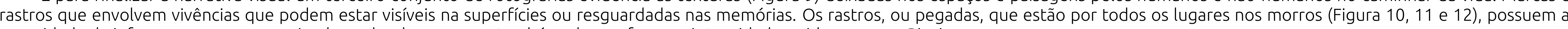
capacidade de informar quem ou que circulou sobre lugar, como também, de que forma e intensidade a vida segue no Pixaim.

\section{REFERÊNCIAS}

BELTING, Hans. Antropologia da imagem paraumaciência da imagem; Lisboa: KKYM+EAUM, 2014.

DESCOLA, Philippe. Além de Natureza e Cultura. In: Tessituras, Pelotas, RS, Vol. 3, N 1, p. 7-33, jan-jun 2015.

Philippe. Outras Naturezas, Outras Culturas. Editora 34, São Paulo, SP, 2016.

MARTINS, José de Souza. Sociologia da Fotografia e da Imagem. Editora Contexto, São Paulo, 2017.

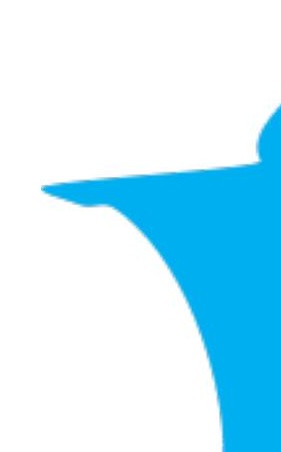

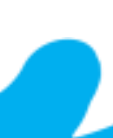
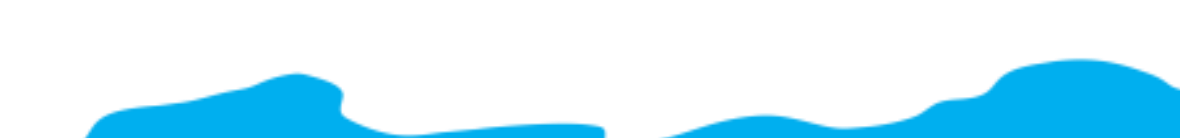

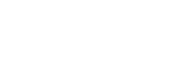
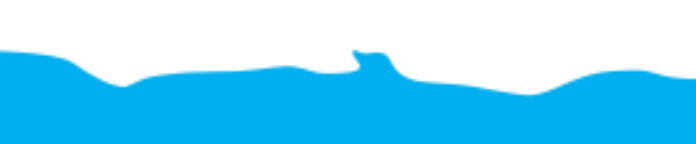